\title{
Vantagens e Desvantagens do Escritório em Edificação Térrea e em Edifício Alto: Um Estudo Exploratório
}

Advantages and Disadvantages of the Office in Single-storey Building and in Tall Building: An Exploratory Study

Ventajas y Desventajas de la Oficina en Edificación de una Sola Planta y en Edificio Alto: Un Estudio Exploratorio

Anne Miskalo Mestranda do Programa de Pós-Graduação em Engenharia de Construção Civil (PPGECC), UFPR, Brasil annemiskalo@ufpr.br

Aloísio Leoni Schmid Professor Doutor, Docente-UFPR, Brasil aloisio.schmid@gmail.com 
RESUMO

O objetivo deste estudo é avaliar, de forma preliminar, as vantagens e desvantagens do escritório em edificação térrea e em edifício alto, por meio da experiência vivida dos participantes da pesquisa; comparar os resultados entre os dois tipos de edificação; bem como avaliar, corrigir e complementar o questionário aplicado, com o propósito de validar o instrumento de pesquisa, a ser utilizado em futuros estudos. Este é um estudo exploratório, no qual realizou-se a coleta de dados por intermédio de um questionário misto, aplicado em 39 estudantes universitários do Programa de Pós-Graduação em Engenharia de Construção Civil da Universidade Federal do Paraná, na cidade de Curitiba-PR, Brasil. Nos resultados, verificou-se nas respostas mais citadas, como vantagens do escritório em edificação térrea: fácil acesso, sem escadas e elevadores, facilidade de fuga e estacionamento; e como desvantagens: ruído, insegurança, visitas indesejadas, alto fluxo de pessoas, cinza dos fumantes e distração. Nas respostas mais citadas, como vantagens do escritório em edifício alto: vista, menos ruído, ventilação, segurança, fluxo de pessoas, status e tranquilidade; e como desvantagens: necessidade de escadas e elevadores, dificuldade de fuga, difícil acesso, dificuldade de locomoção e estacionamento. Além disso, observou-se pela comparação dos resultados da pesquisa, que foram citadas mais vantagens e menos desvantagens do escritório em edifício alto em relação ao escritório em edificação térrea.

PALAVRAS-CHAVE: Escritório. Edificação térrea. Edifício alto.

\section{ABSTRACT}

The aims of this study is to evaluate, in a preliminary way, the advantages and disadvantages of the office in a single-storey building and in a tall building, through the lived experience of the participants; compare the results between the two types of building; as well as evaluate, correct and complement the applied questionnaire, with the purpose of validating the research instrument, to be used in future studies. This is an exploratory study, in which the data were collected through a mixed questionnaire, applied to 39 university students of the Post-Graduation Program in Civil Construction Engineering of the Federal University of Paraná, in the city of Curitiba-PR, Brazil. In the results, it was verified in the most cited answers, as advantages of the office in a single-storey building: easy access, without stairs and elevators, ease of escape and parking; and as disadvantages: noise, insecurity, unwanted visits, high flow of people, smokers' gray and distraction. In the most cited answers, as advantages of office in tall building: view, less noise, ventilation, security, flow of people, status and tranquility; and as disadvantages: the need for stairs and elevators, difficulty of escape, difficult access, difficulty of locomotion and parking. In addition, it was noted by comparing survey results, that were cited more advantages and fewer disadvantages of the office in tall building compared to the office in single-storey building.

Keywords: Office. Single-storey building. Tall building.

\section{RESUMEN}

El objetivo de este estudio es evaluar, de forma preliminar, las ventajas y desventajas de la oficina en edificación de una sola planta y en edificio alto, por medio de la experiencia vivida de los participantes de la investigación; comparar los resultados entre los dos tipos de edificación; así como evaluar, corregir y complementar el cuestionario aplicado, con el propósito de validar el instrumento de investigación, a ser utilizado en futuros estudios. Este es un estudio exploratorio, en el cual se realizó la recolección de datos por intermedio de un cuestionario mixto, aplicado en 39 estudiantes universitarios del Programa de Postgrado en Ingeniería de Construcción Civil de la Universidad Federal de Paraná, en la ciudad de Curitiba-PR, Brasil. En los resultados, se verificó en las respuestas más citadas, como ventajas de la oficina en edificación de una sola planta: fácil acceso, sin escaleras y ascensores, facilidad de fuga y estacionamiento; y como desventajas: ruido, inseguridad, visitas no deseadas, alto flujo de personas, gris de cigarrillo y distracción. En las respuestas más citadas, como ventajas de la oficina en edificio alto: vista, menos ruido, ventilación, seguridad, flujo de personas, status y tranquilidad; y como desventajas: necesidad de escaleras y elevadores, dificultad de fuga, difícil acceso, dificultad de locomoción y estacionamiento. Además, se observó por la comparación de los resultados de la investigación, que fueron citadas más ventajas y menos desventajas de la oficina en edificio alto en relación a la oficina en edificación de una sola planta.

PALABRAS-CLAVE: Oficina. Edificación de una sola planta. Edificio alto. 


\section{ANAP Brasil \\ ISSN 1984-3240 \\ v. 10, n. 21}

\section{REVISTA CIENTIFICA 2017}

\section{INTRODUÇÃO}

As pessoas passam a maior parte de suas vidas em ambientes internos, como em suas casas, locais de trabalho e em outros edifícios (MONTEIRO et al., 2015). Para muitas pessoas, pelo menos um terço do seu tempo, 8 das 24 horas do dia, é decorrido no local de trabalho, especificamente no escritório (CHANG; CHEN, 2005).

O termo escritório, assim como bureau, no idioma francês e inglês, tem a sua origem em uma peça do mobiliário: a escrivaninha, a qual ocupava gabinetes privativos, quase secretos, onde realizavam-se atividades consideradas como intelectuais e de alto valor, tal como a escrita, a contabilidade e o projeto (CALDEIRA, 2005).

Edificação térrea é a construção de um pavimento, podendo possuir mezaninos cuja somatória de áreas deve ser menor ou igual à terça parte da área do piso de pavimento (CSCIP, 2015).

Para um edifício ser considerado alto, a definição mínima é ter altura maior que três pavimentos (GIFFORD, 2007). Também é especificado no Código de Obras e Código de Segurança Contra Incêndio de cada país, região, estado ou cidade onde o edifício está localizado, a altura exata acima da qual um edifício é considerado alto (CRAIGHEAD, 2009). Além disso, o Council Tall Buildings and Urban Habitat (CTBUH) desenvolveu padrões internacionais para medir e definir edifícios altos, considerando uma ou mais das seguintes categorias: altura relativa ao contexto, proporção e se contém tecnologias relevantes para edifícios altos (CTBUH, 2017).

De acordo com Schmid (2008), o ambiente urbano a $5 \mathrm{~m}$ de altura difere fundamentalmente daquele a $100 \mathrm{~m}$ de altura, entretanto, costumam receber plantas e vedações iguais.

A verticalização pode ser indicada como exemplo de materialização das transformações técnicas que atingem as cidades contemporâneas de forma decisiva (RAMIRES, 1998). Por meio da verticalização um número elevado de atividades centrais concentram-se em reduzida extensão territorial, sendo uma das formas de crescimento do centro; o qual vêm-se apresentando como um aglomerado de edifícios, principalmente comerciais (MACHADO; MÉNDES, 2003). Desde 1930 até 2010 (classificados por décadas), a atividade com maior percentual era a de escritórios nos 100 edifícios mais altos do mundo (SHEHADI et. al, 2016).

As vantagens econômicas do edifício alto sobre o valor do solo tem sido a mais importante força de transformação da forma urbana desde meados do século passado até os dias de hoje, criando lugares emblemáticos da modernidade, como Nova lorque, Chicago e Hong Kong (GONÇALVES et. al, 2015). Entretanto, os edifícios altos não só satisfazem uma necessidade funcional, mas também são fontes de orgulho nacional e identidade cultural (KOLVIR; DOMOLA, 2015).

Na literatura, destacam-se estudos que abordam o edifício alto de habitação e a sua influência em seus ocupantes, no qual citam-se pesquisas por Fanning (1967), Gifford (2001), Evans (2003), Evans et al., (2003), Yuen (2005) e Gifford (2007). Porém, os estudos relacionando os trabalhadores de escritórios em edificação térrea e em edifício alto são escassos. 


\section{OBJETIVOS}

O objetivo deste estudo é avaliar, de forma preliminar, as vantagens e desvantagens do escritório em edificação térrea e em edifício alto, por meio da experiência vivida dos participantes da pesquisa; comparar os resultados entre os dois tipos de edificação; bem como avaliar, corrigir e complementar o questionário aplicado, com o propósito de validar o instrumento de pesquisa, a ser utilizado em futuros estudos.

\section{METODOLOGIA}

A presente pesquisa consiste de um estudo exploratório, por meio de um levantamento de opinião, com abordagem qualitativa. Investigou-se, por meio da experiência vivida dos participantes, significados e opiniões a respeito do tema pesquisado. Conforme Günther (2003), as três principais técnicas para compreender o comportamento humano em ciências sociais empíricas são: (1) observar o comportamento que ocorre naturalmente no âmbito real, (2) criar situações artificiais e observar o comportamento perante tarefas definidas para essas situações e (3) perguntar às pessoas sobre o que fazem, fizeram e sobre o que pensam, pensaram.

\subsection{Participantes}

Participaram da pesquisa 39 estudantes universitários do Programa de Pós-Graduação (mestrado e doutorado) em Engenharia de Construção Civil (PPGECC) da Universidade Federal do Paraná (UFPR), na cidade de Curitiba-PR, Brasil.

\subsection{Instrumento de coleta de dados}

Utilizou-se um questionário misto, composto por perguntas abertas, fechadas e de múltipla escolha. As perguntas foram organizadas em categorias, como a caracterização física do local de trabalho (número do pavimento e layout), vantagens e desvantagens do escritório em edificação térrea e em edifício alto e dados pessoais do participante (gênero e idade).

\subsection{Procedimento}

Inicialmente a examinadora explicou o propósito do estudo e o procedimento da pesquisa. A escolha dos participantes não foi aleatória, mas influenciada pela disponibilidade dos indivíduos em colaborarem para o estudo. Com a permissão, cada participante recebeu o questionário para preencher individualmente, com base em suas próprias percepções e

experiências vividas, sem necessidade de identificação. O tempo aproximado de duração do 


\section{REVISTA CIENTIFICA 2017}

preenchimento do questionário foi inferior a 40 minutos.

Aplicou-se o questionário no dia 12 de abril de 2017 nas dependências do PPGECC da UFPR. Após a coleta de dados, realizou-se a tabulação, a análise e a comparação dos resultados das respostas referente as vantagens e desvantagens de um escritório em edificação térrea e em edifício alto.

\section{RESULTADOS}

\subsection{Características gerais dos participantes}

Na Tabela 1 apresenta-se as características gerais dos participantes em relação ao gênero e faixa etária.

Tabela 1- Características gerais dos participantes ( $n=39)$ em relação ao gênero e faixa etária

\begin{tabular}{|c|c|c|}
\hline VARIÁVEIS & $n$ & $\%$ \\
\hline \multicolumn{3}{|l|}{ Gênero } \\
\hline Feminino & 20 & 51 \\
\hline Masculino & 19 & 49 \\
\hline \multicolumn{3}{|l|}{ Faixa etária } \\
\hline 20 a 30 anos & 29 & 74 \\
\hline 31 a 40 anos & 5 & 13 \\
\hline 41 a 50 anos & 2 & 5 \\
\hline 51 a 60 anos & 3 & 8 \\
\hline
\end{tabular}

Observa-se na Tabela 1 que o gênero da amostra estudada é aproximadamente uniforme, sendo $51 \%$ do sexo feminino e $49 \%$ do sexo masculino. Com relação a faixa etária, o maior percentual dos participantes está compreendido entre 20 a 30 anos (74\%), seguido de 31 a 40 anos (13\%), 51 a 60 anos (8\%) e 41 a 50 anos (5\%).

\subsection{Caracterização do local de trabalho atual}

A Tabela 2 demonstra a caracterização do local de trabalho atual dos participantes em relação ao pavimento e layout. 


\section{ANAP Brasil \\ ISSN 1984-3240 \\ v. 10, n. 21}

\section{REVISTA CIENTIFICA 2017}

Tabela 2- Caracterização do local de trabalho dos participantes em relação ao pavimento e layout

\begin{tabular}{lcc}
\multicolumn{1}{c}{ VARIÁVEIS } & $\mathbf{n}$ & \% \\
\hline Pavimento & $\mathbf{3 6}$ & 78 \\
Térreo ou no 2o pavimento de uma edificação & 28 & 22 \\
3o pavimento ou superior de uma edificação & 8 & \\
Layout & 38 & 61 \\
Divisórias e/ou paredes & 23 & 34 \\
Planta-livre & 13 & 5 \\
Misto (divisórias e/ou paredes e com planta-livre) & 2 &
\end{tabular}

Na Tabela 2 constata-se que a maioria dos participantes trabalham em um escritório térreo ou no 2 o pavimento de uma edificação (78\%), enquanto $22 \%$ trabalham em um escritório no 3 o pavimento ou superior de uma edificação. Utilizou-se a classificação do pavimento de acordo com Gifford (2007), o qual define que para um edifício ser considerado alto é necessário ter altura maior que três pavimentos.

Sobre o layout do ambiente de trabalho, verifica-se que $61 \%$ dos participantes trabalham em um ambiente com divisórias e/ou paredes, 34\% em planta-livre e 5\% em um ambiente misto (divisórias e/ou paredes e com planta-livre).

\subsection{Análise das perguntas abertas do questionário}

Utilizou-se a experiência vivida dos participantes como critério para que pudessem responder as duas perguntas abertas do questionário, ou seja, era necessário que os participantes já tivessem a experiência de ter trabalhado em um escritório térreo e/ou em edifício alto.

A experiência é um conhecimento adquirido com a prática (AMATUZZI, 2007). Além disso, segundo Elali (1997), sob aspectos perceptuais da relação pessoa-ambiente, considera-se que o contato direto e cotidiano de um usuário com um objeto transforma esse indivíduo em um crítico severo e abalizado daquele produto.

A Tabela 3 apresenta o $\mathrm{n}$ de participantes que responderam as perguntas abertas referente às vantagens e desvantagens do escritório térreo e em edifício alto. 


\section{ANAP Brasil \\ ISSN 1984-3240 \\ v. 10, n. 21}

\section{REVISTA CIENTIFICA 2017}

Tabela 3- Participantes que responderam as perguntas abertas referente às vantagens $e$ desvantagens do escritório térreo e em edifício alto

\begin{tabular}{|c|c|c|}
\hline VARIÁVEIS & n & $\begin{array}{l}\text { QUANTIDADE DE } \\
\text { MENÇÕES }\end{array}$ \\
\hline \multicolumn{3}{|l|}{ Térreo } \\
\hline Vantagens & 32 & 40 \\
\hline Desvantagens & 29 & 36 \\
\hline \multicolumn{3}{|l|}{ Edifício alto } \\
\hline Vantagens & 30 & 54 \\
\hline Desvantagens & 29 & 33 \\
\hline
\end{tabular}

Obs: $\mathrm{n}=$ amostra que respondeu a pergunta.

Nota-se na Tabela 3 que 32 participantes já trabalharam ou trabalham em um escritório térreo; e 30 participantes já trabalharam ou trabalham em um escritório de um edifício alto. Esse resultado demonstra equilíbrio entre as amostras de trabalhadores em escritório térreo e em

edifício alto, o qual proporciona uma melhor comparação dos resultados.

Verifica-se a quantidade de menções nas respostas: sobre as vantagens, no escritório térreo em $n=32$, menções= 40; e no escritório em edifício alto em $n=30$, menções $=54$. A respeito das desvantagens, no escritório térreo em $n=29$, menções=36; e no escritório em edifício alto em $\mathrm{n}=29$, menções=33.

Observa-se pela comparação dos resultados, que no escritório em edifício alto foram citadas mais vantagens e menos desvantagens em relação ao escritório térreo.

\section{a) Escritório térreo}

Sobre a pergunta: "Se você já trabalhou ou trabalha em um escritório térreo, favor citar as vantagens e desvantagens". A Figura 1 apresenta as vantagens, conforme as menções mais citadas pelos participantes, do escritório térreo. 


\section{ANAP Brasil \\ ISSN 1984-3240 \\ v. 10, n. 21}

\section{REVISTA CIENTIFICA 2017}

Figura 1: Vantagens do escritório térreo segundo os participantes

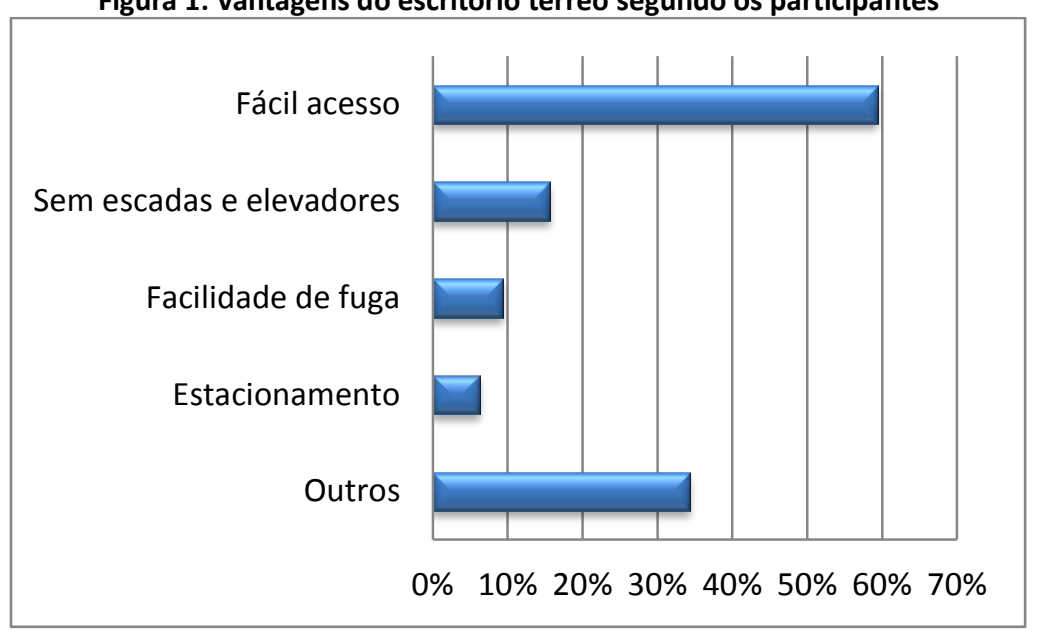

Obs: \% inclui apenas respostas válidas para esta pergunta, $n=32$.

Observa-se na Figura 1, quanto às vantagens do escritório térreo, em 40 menções, os termos mais citados foram: fácil acesso / acessibilidade a outros setores é melhor / facilidade de acesso / acesso rápido / acesso é melhor / facilidade / circulação de pessoas para entrada/saída facilitada / tempo de chegar na saída / proximidade com a saída / menor deslocamento (59\%), não precisar de escada e elevador / sem escadas / não tem escadaria ou elevador / ausência da necessidade de escadas / evitar escadas e/ou elevadores (16\%), facilidade de fuga em caso de emergência / saída mais fácil em caso de incêndio / saída mais fácil em caso de queda de luz (9\%), estacionamento facilitado / não ter custo de estacionamento (6\%) e outros (34\%).

Seguem algumas menções dos participantes:

"Saída mais fácil em caso de queda de luz, de incêndio, de acesso ao edifício".

"Acesso mais fácil para atendimento pessoal, facilidade de fuga em caso de emergência".

"Não tem escadaria ou elevador, arejado e claro".

"Menor deslocamento, proximidade com a saída, temperatura menor".

A Figura 2 indica as desvantagens, segundo as menções mais citadas pelos participantes, do escritório térreo. 


\section{ANAP Brasil \\ ISSN 1984-3240 \\ v. 10, n. 21}

\section{REVISTA CIENTIFICA 2017}

Figura 2: Desvantagens do escritório térreo segundo os participantes

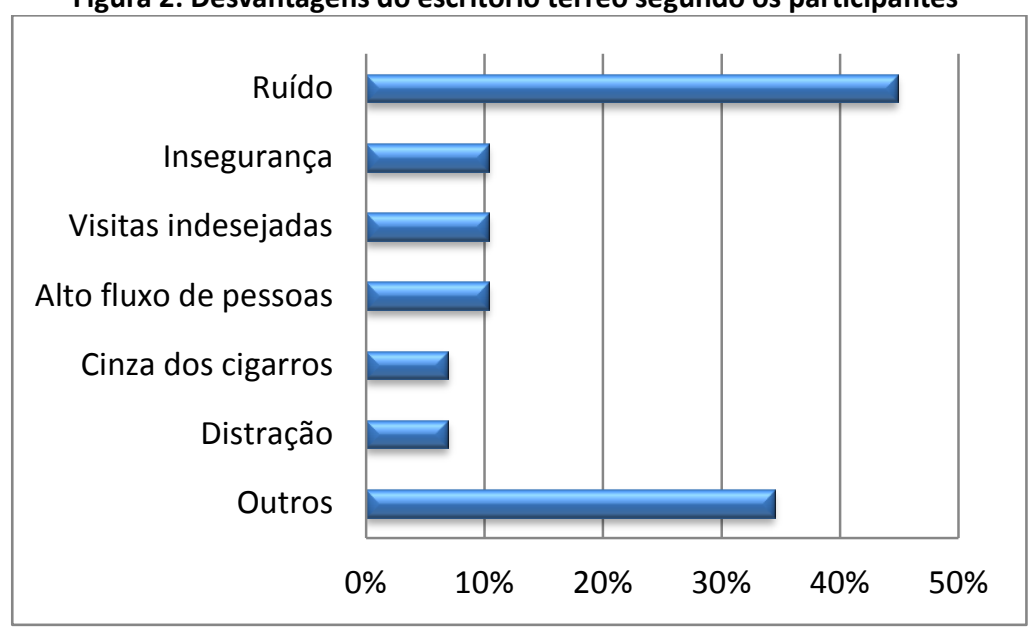

Obs: \% inclui apenas respostas válidas para esta pergunta, $n=29$.

Nota-se na Figura 2, em relação às desvantagens do escritório térreo, em 36 menções, os termos mais citados foram: ruído / barulho das ruas / barulho externo / excesso de ruídos / barulho do trânsito de veículos / barulho da rua e trânsito / barulho / barulho das pessoas circulando (45\%), insegurança / poder ser assaltado a qualquer hora / segurança (10\%) visitas indesejadas / possibilidade de virar central de informações / acesso fácil das outras pessoas (10\%), muito tráfego de pessoas / alto fluxo de pessoas / trânsito de pessoas (10\%), cinza dos fumantes ao lado da janela / cigarro (7\%), distração / desvio de atenção (7\%) e outros (34\%).

Transcreve-se algumas respostas dos participantes:

"Excesso de ruídos, falta de uma vista ampla do exterior".

"Perto da rua, barulho, cinza dos fumantes ao lado da janela".

"Desvio de atenção devido à acontecimentos no entorno e barulho da rua".

"Pouco iluminado. Dá para escutar o barulho das pessoas circulando".

\section{b) Escritório em edifício alto}

Sobre a pergunta: "Se você já trabalhou ou trabalha em um escritório de um edifício alto, favor citar as vantagens e desvantagens". A Figura 3 apresenta as vantagens, conforme as menções mais citadas pelos participantes, do escritório em edifício alto. 


\section{REVISTA CIENTIFICA 2017}

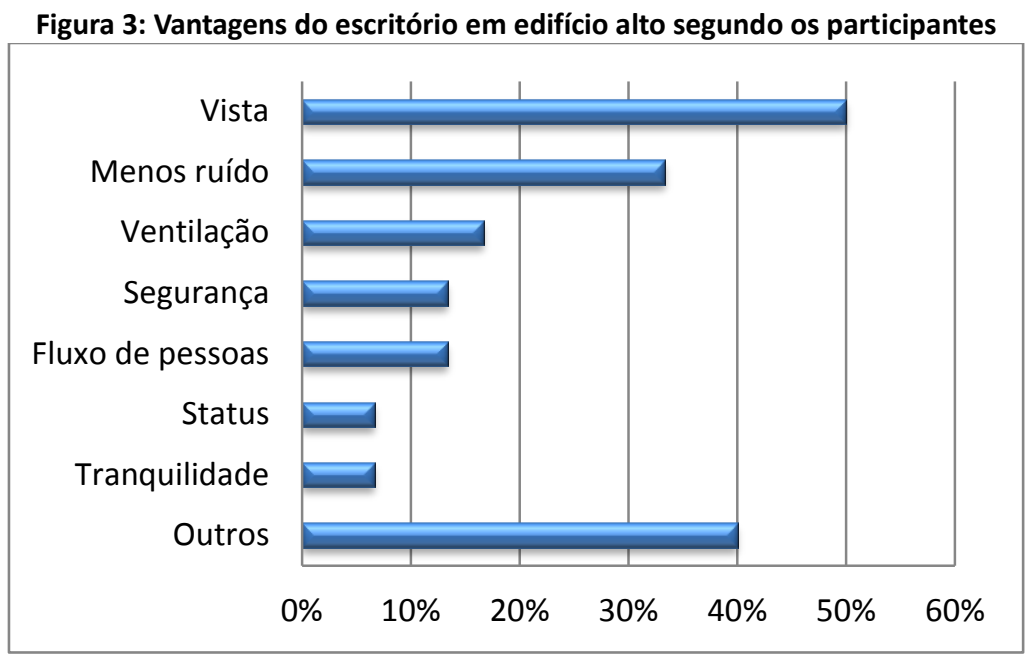

Obs: \% inclui apenas respostas válidas para esta pergunta, $n=30$.

Identifica-se na Figura 3, a respeito das vantagens do escritório em edifício alto, em 54 menções, os termos mais citados foram: vista / bela vista / vista do ambiente externo / vista do ambiente (janela) / vista diferenciada / vista bonita / vista da cidade e do horizonte / vista agradável / paisagem agradável e relaxante (50\%), menor poluição sonora / menos barulho / menos ruído / conforto acústico / silêncio (33\%), arejado / ventilação (17\%), segurança (13\%), circulação de pessoas / fluxo de pessoas / menos trânsito de pessoas / não ser interrompido pela entrada e saída de pessoas o tempo todo (13\%), status / mais exclusivo (7\%), calma / tranquilidade (7\%) e outros (40\%).

Transcreve-se algumas respostas:

"Vista, conforto acústico e status".

"Menos barulho, circulação de pessoas, ventilação e vista".

"A vista do ambiente externo, normalmente, ajuda a 'limpar' os pensamentos".

"Silêncio, o escritório se mantém mais limpo e creio que proporciona melhor iluminação e ventilação".

A Figura 4 indica as desvantagens, segundo as menções mais citadas pelos participantes, do escritório em edifício alto. 


\section{ANAP Brasil \\ ISSN 1984-3240 \\ v. 10, n. 21}

\section{REVISTA CIENTIFICA 2017}

Figura 4: Desvantagens do escritório em edifício alto segundo os participantes

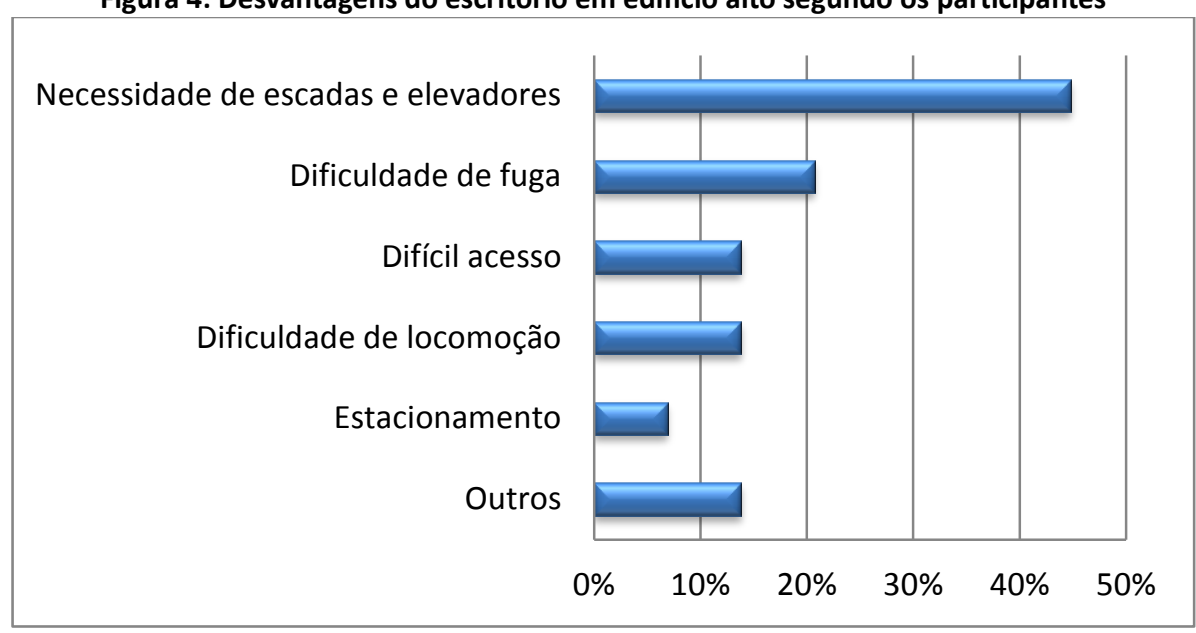

Obs: \% inclui apenas respostas válidas para esta pergunta, $n=29$.

Observa-se na Figura 4, com relação às desvantagens do escritório em edifício alto, em 33 menções, os termos mais citados foram: escadarias / necessidade de elevador / demora ao usar o elevador / problemas com o trajeto (elevador e escada) / díficil acesso (elevador/escada) (45\%), saída congestionada em caso de incêndio / em caso de incêndio a saída pode ser mais demorada / acesso e saída com falta de energia elétrica / perigo em caso de catástrofe / dificuldade de estabelecer rotas de fuga em caso de emergência / dificuldade de saída rápida da edificação (21\%), acesso / acesso lento / dificuldade de acesso (14\%), locomoção / dificuldade de locomoção / muito esforço para locomover objetos pesados / distribuição de equipamentos (plotters, impressoras) (14\%), estacionamento (7\%) e outros (14\%).

Transcreve-se algumas respostas:

"Escadarias, muito esforço para locomover objetos pesados".

"Elevador ou escadas para chegar ao local. Elevador cheio, demorado ou muitos lances de escada".

"Em caso de incêndio a saída pode ser mais demorada. Sou brigadista".

\subsection{Comparativo das respostas sobre o escritório em edificação térrea e em edifício alto}

Para auxiliar na descoberta e possíveis relações entre as respostas das perguntas abertas, agrupou-se as menções com maior frequência nas respostas de cada pergunta, conforme demonstrado no Quadro 1. 


\section{ANAP Brasil \\ ISSN 1984-3240 \\ v. 10, n. 21}

\section{REVISTA CIENTIFICA 2017}

Quadro 1: Respostas das Perguntas Abertas do Questionário com a Maior Quantidade de Menções

\begin{tabular}{|c|c|c|c|c|c|c|c|c|c|}
\hline \multicolumn{10}{|c|}{ Vantagens do escritório térreo de acordo com os respondentes } \\
\hline Fácil a & & em escadas e eleva & adores & & Facilidac & def & & Est & acionamento \\
\hline \multicolumn{10}{|c|}{ Desvantagens do escritório térreo de acordo com os respondentes } \\
\hline Ruído & Insegurança & Visitas indesejadas & & Alto fluxo de & pessoas & Cin & dos cigarros & & Dist \\
\hline \multicolumn{10}{|c|}{ Vantagens do escritório em edifício alto conforme os respondentes } \\
\hline Vista & Menos ruído & Ventilação & Segura & ança & uxo de pes & & Status & & idade \\
\hline \multicolumn{10}{|c|}{ Desvantagens do escritório em edifício alto conforme os respondentes } \\
\hline $\begin{array}{l}\text { Necess } \\
\text { e eleva }\end{array}$ & $\begin{array}{l}\text { de de esc } \\
\text { es }\end{array}$ & $\begin{array}{l}\text { Dificuldade } \\
\text { fuga }\end{array}$ & de & aces & Dif & & omoção & & Estacion \\
\hline
\end{tabular}

No Quadro 1, identifica-se que algumas características descritas como vantagens do escritório térreo (fácil acesso, sem escadas e elevadores, facilidade de fuga e facilidade e sem custo de estacionamento) são consideradas desvantagens no escritório em edifício alto (difícil acesso, necessidade de escadas e elevadores, dificuldade de fuga e falta e custo de estacionamento).

Da mesma forma ocorreu com relação à algumas características descritas como desvantagens do escritório térreo (ruído, insegurança e alto fluxo de pessoas) e as vantagens do escritório em edifício alto (menos ruído, segurança e fluxo de pessoas). Além disso, observa-se que a vista foi mencionada somente no escritório em edifício alto, o que pode indicar uma particularidade de destaque nesse tipo de edificação.

\subsection{Análise do instrumento de pesquisa}

$\mathrm{Na}$ análise dos dados, após a tabulação, identificou-se algumas falhas existentes no questionário, com a necessidade de alterar e complementar o instrumento de pesquisa com mais perguntas sobre o ambiente de trabalho e a respeito do participante.

Verificadas as falhas reformulou-se o questionário tendo em vista próximos estudos. Explicitou melhor a redação de alguns itens, resultando no aprimoramento do instrumento de pesquisa. Assim, por meio do estudo-piloto, tem-se um novo questionário, possivelmente capaz de abordar com mais clareza as questões propostas.

\section{CONCLUSÃO}

Observou-se pela comparação dos resultados da pesquisa, que foram citadas mais vantagens e menos desvantagens no escritório em edifício alto em relação ao escritório em edificação térrea. Verificou-se nas respostas sobre as vantagens do escritório térreo em $n=32$, menções= 40; e do escritório em edifício alto em $n=30$, menções $=54$. A respeito das desvantagens, no escritório térreo em $n=29$, menções=36; e no escritório em edifício alto em $n=29$, menções=33. Além disso, identificou-se que as vantagens do escritório térreo mais mencionadas (fácil acesso, sem escadas e elevadores, facilidade de fuga e facilidade e sem custo de estacionamento) são consideradas desvantagens no escritório em edifício alto (difícil acesso, necessidade de escadas e elevadores, dificuldade de fuga e falta e custo de estacionamento). 


\section{ANAP Brasil \\ ISSN 1984-3240 \\ v. 10, n. 21}

\section{REVISTA CIENTIFICA 2017}

O questionário utilizado no teste-piloto do presente estudo contribuiu para a investigação das vantagens e desvantagens do escritório em edificação térrea e em edifício alto, por meio da experiência vivida dos participantes da pesquisa.

O estudo-piloto demonstrou a necessidade de aprimoramento do instrumento de pesquisa em algumas questões. Assim, realizou-se a correção e complementação do questionário para validá-lo como um instrumento de pesquisa mais eficiente.

A aplicação do método do presente estudo em trabalhadores de escritórios (térreo e em edifício alto), poderá auxiliar no aprimoramento de ideias e na criação de hipótese sobre a percpeção dos trabalhadores em relação ao local de trabalho. Por ser um instrumento de rápida e fácil aplicação, o questionário revelou seu potencial.

\section{AGRADECIMENTO}

À Universidade Federal do Paraná, ao Programa de Pós-Graduação em Engenharia de Construção Civil (PPGECC-UFPR) e aos estudantes universitários que participaram da pesquisa.

\section{REFERÊNCIAS BIBLIOGRÁFICAS}

AMATUZZI, M. Experiência: um termo chave para a Psicologia. Memorandum, v. 13, p. 8-15, 2007. Disponível em: <http://www.fafich.ufmg.br/ memorandum/a13/amatuzzi05.pdf>. Acesso em: 15 fev. 2017.

CALDEIRA, V. Ambientes de trabalho. Revista Arquitetura e Urbanismo, n. 133, abr., 2005.

CHANG, C. Y.; CHEN, P. K. Human response to window views and indoor plants in the workplace. Hortscience, v. 40, n.5, p.1354-1359, Aug. 2005.

CRAIGHEAD, G. High-rise security and fire life safety. 3. ed. Burlington: Elsevier, 2009.

CSCIP. Código de segurança contra incêndio e pânico. Disponível em:

<http://www.bombeiros.pr.gov.br/arquivos/File/CSCIP2015/CSCIP_versao_2015.pdf>. Acesso em: 06 jun. 2017.

CTBUH. Council on Tall Buildings and Urban Habitat. CтBUH Height Criteria: for Measuring \& Defining Tall Buildings. Disponível em: <http://www.ctbuh.org/HighRiselnfo/TallestDatabase/Criteria/tabid/446/language/enGB/Default.aspx>. Acesso em: 02 jun. 2017.

ELALI, G. A. Psicologia e Arquitetura: em busca do locus interdisciplinar. Estudos de Psicologia, v. 2, n. 2, p. 349-362, 1997.

EVANS, G. W. The built environment and mental health. Journal of Urban Health: Bulletin of the New York Academy of Medicine, v. 80, n. 4, Dec. 2003.

EVANS, G. W.; WELLS, N. M.; MOCH, A. Housing and mental mealth: a review of the evidence and a methodological and Conceptual Critique. Journal of Social Issues, p. 475-500, 2003.

FANNING, D. M. Families in flats. British Medical Journal, p. 382-386, 1967.

GIFFORD, R. Residential environmental psychology. In: SMELSER, N. J.; BALTES, P. B. (Eds.). International Encyclopedia os the Social \& Behavioral Sciences, 2001. 


\section{REVISTA CIENTIFICA 2017}

GIFFORD, R. The consequences of living in high-rise buildings. Architectural Science Review, v. 50, n.1, March, 2007.

GONÇALVES, J. C. S.; MELLO, M.; MIANA, A. C.; ROSA, M. L. Edifícios altos e forma urbana. In: GONÇALVES, J. C. S.; BODE, K (Orgs.). Edifício ambiental. São Paulo: Oficina de Textos, 2015.

GÜNTHER, H. Como elaborar um questionário. Série: Planejamento de Pesquisa nas Ciências Sociais. Brasília, n.1, UnB, Laboratório de Psicologia Ambiental, 2003.

KOLVIR, H. R.; DOMOLA, H. M. The study of Environmental Psychology in tall buildings with sustainable architecture Approach. Architecture Research, v. 5, n. 3, p. 102-105, 2015.

MACHADO, J. R.; MÉNDES, C. M. O processo de verticalização do centro de Maringá-PR, Brasil. Investigaciones Geográficas, Boletín del Instituto de Geografía-UNAM, n. 52, p. 53-71, 2003.

MONTEIRO, L. M.; BITTENCOURT, L.; YANNAS, S. Arquitetura da adaptação. In: GONÇALVES, J. C. S.; BODE, K (Orgs.). Edifício ambiental. São Paulo: Oficina de Textos, 2015.

RAMIRES, J. C. L. O processo de verticalização das cidades brasileiras. Boletim de Geografia, Maringá, v. 16, n. 1, p. 97-105, 1998.

SCHMID, A. L. Edifícios altos: a regularidade das aberturas (de cima até embaixo) questionada do ponto de vista ambiental. Arquitextos, São Paulo, v.8, n. 094.02, mar. 2008.

SHEHADI, A.; URSINI, S.; GEROMETTA, M. 2016 Another Record-Breaker for Skyscraper Completions; 18 "Tallest Titles" Bestowed. Council on Tall Buildings and Urban Habitat - CTBUH. Disponível em: <

http://www.skyscrapercenter.com/research/CTBUH_ResearchReport_2016YearlnReview.pdf>. Acesso em: 02 jun. 2017.

YUEN, B. Romancing the high-rise in Singapore. Cities, v. 22, n. 1, p. 3-13, 2005. 